\title{
Assessment of Geological Environment Carrying Capacity of Ankang Region Basin on the Improved Weighted Composite Index Method
}

\author{
Song Yaya ${ }^{1, *}$, Zhang Hangbo ${ }^{1}$, and Wang Youlin ${ }^{1}$ \\ ${ }^{1}$ Shanxi Center of Geological Survey,Xi'an,710068,China
}

\begin{abstract}
Considering the geological and regional feature of Ankang region, combining target analysis, feature, the assessment system of geological environment bearing capacity was established, and the weights assessment indexes were presented by Analytic Hierarchy Process ( AHP). And weighted composite index method combined GIS spatial analysis with data attributes database management method were adopted to assess the geo-environment carrying capacity of Ankang region. Based on the evaluation results and analysis of each rate area, this paper provides the scientific basis for ecological civilization construction and sustainable development.
\end{abstract}

\section{Geological environment capacity evaluation model}

The status evaluation of geological environment capacity is a part of the national resources and environment capacity evaluation and regionalization, including ecological environmental capacity evaluation, geological environment carrying capacity and climate environment evaluation ${ }^{[1-2]}$. Carrying out the Status evaluation of geological environment capacity will provide comprehensive basic support for land resources planning and development of major functional areas and for geological environmental benign evolution and realizing human's biggest social benefit, environmental safety and economic benefits, and it is an urgent requirement for scientific planning, rational development and protection of land and resources ${ }^{[3-4]}$.

\subsection{Regional general situation}

Ankang city is located in the south of Shaanxi province, with complex geological environment conditions. It is bounded by the han river and the Yuehe river. In the north, it belongs to the Qin ling mountains, and in the south, it is along the remaining veins of Bashan mountain. The main physiognomy consists of floodplain, river valley terrace, erosion accumulation platform and low mountain and its main lithology includes silty clay, silty clay, clay, medium sand, coarse sand, gravel sand, pebble, round gravel and 1000 rocks. Ankang city is located in the boundary zone between the Qinling tectonic belt and the Bashan arc structural belt, and the branch fault of Bashan arc and the middle part of Yuehe fault crosses the boundary, which is easy to generate and induce earthquakes. The geological environment is damaged and geological disasters happen frequently due to the limitation of geological environment and the overexploitation of geological environment. In view of the geological environment problems in this region, it is of great guiding and practical significance to carry out the evaluation of the current geological environment carrying capacity, solve the related problems of regional development, adjust the social and economic activities of this region and the development of geological environment, and realize the sustainable development of natural environment and social economy. Through the analysis of the geological survey data and literatures in the past, it is concluded that the geological environment problems in this area mainly include collapse, landslide, debris flow and soil erosion, which have a certain negative impact on human survival and social development.

\subsection{The model of geological environmental capacity in Ankang region}

The geological environment capacity is the most important ability to withstand the effects and changes of human activity in the geological environment, and its size is related to the geological environment and the quality of the environment, and it can reflect the relationship between people and places in the region ${ }^{[5]}$. At the end of the 20th century, domestic scholars began to study the regional geological environment, and the study was regional resource and environment elements synthesis.

* Corresponding autho: syy409@163.com 
Later the object was focused on point poly condensation, and its evaluation index system and method was carried out. The methods of geological environmental capacity are often divided into qualitative, semi-quantitative and quantitative, and, of course, the semi-quantitative method is the most popular method. At present, the study on the geological environment capacity is mainly qualitative description, and the evaluation index system and quantitative evaluation model are relatively few. On the basis of the synthetic index method, it is planned to construct the comprehensive index method based on the limit coefficient to reflect the influence of strong limit and strong limiting factor. The model has certain advantages considering the various indexes, with limit factor is quantified, which combine experience both empirical qualitative and scientific quantitative reasonable.

The key to the evaluation of geological environment capacity is to form a model which can reflect the overall characteristics of the system and quantify the quality of the geological environment. Considering the limitation degree of land development and geological environment protection, on the basis of comprehensive index method, the influence of mandatory and more mandatory factors on system evaluation is represented by the restriction coefficient.

The evaluation model is as follows:

$$
E=\prod_{j=1}^{m} F_{j} * \sum_{k=1}^{n} w_{k} * f_{k}
$$

Where, $\mathrm{E}$ is the evaluation score of suitability, which represents the level of safety and geological environment capacity. The higher the score is, the worse the suitability and function of the system, and the lower the level of safety and capacity.j is the number of strong restrictive factors. In the geological environment system, restrictive factors include active faults (earthquakes of magnitude 8 or above can occur), affected areas, ungovernable mined-out subsidence areas, and geological relics. Based on the comprehensive assessment of structural stability and geological hazard vulnerability, only one index of geological relics was finally determined, and the rest were all relatively mandatory factors. $\mathrm{Fj}$ is the $\mathrm{j}$ influence factor (including mandatory and non-mandatory factors). For mandatory factor $F$, the value is 0 , and the strong factor is 1 for 1 , and $\mathrm{j}$ value is $1 \sim 7 . f_{k}$ is the $\mathrm{k}$ index value, $w_{k}$ is the weight of the $\mathrm{k}$ more mandatory factor, $\mathrm{k}$ is the number of more mandatory factor, and the value is $1-7 . \mathrm{M}$ is the number of strong restrictive factors, and $n$ is the number of more mandatory factors.

The realization of the evaluation model is mainly based on the spatial analysis function of MapGis. By establishing the evaluation result layer of each single index, the acquisition of each index value can be realized.

\section{The construction of index system and the determination of index weight}

\subsection{Evaluation index system}

Through subjective qualitative determination, the objective analysis method is adopted, which is decomposed layer by layer from the target layer, criterion (constraint) layer and element layer until the decomposed sub-target can be measured by quantitative (semi-quantitative) or qualitative independent indicators. According to the research status at home and abroad, and the influence factors of the geological environment problem in AnKang region, the demand analysis of the land planning is based on the space conditions, resource conditions, constraints and advantages of the geological environment, and the identification factors, the identification factors include geological disasters, structural stability, soil and water environment conditions, shallow geothermal and geological relics.

Geologic hazard factors are indicated by 6 factors affecting the extent of geological calamity (geomorphology, rock type, grade, structure, annual rainfall and human engineering activities). Regional structural stability is represented by regional active fault and peak acceleration of ground motion. The soil and water environment conditions are expressed by the diving quality and soil erosion modulus. The shallow geothermal elements are represented by the optimum levels of the shallow geothermal, including hydrogeological conditions and thermal characteristics of the strata. Geological relics are the restrictive and resourceful conditions of the development process, and they are represented by the classifications of the relics. There are 16 factors involved in basic geological conditions, engineering geological conditions, hydrogeological conditions, and so on (see table 1).

Table 1 Evaluation index system

\begin{tabular}{|c|c|c|c|}
\hline Target layer & Criterion layer (constraint layer) & \multicolumn{2}{|c|}{ Index layer } \\
\hline \multirow{7}{*}{$\begin{array}{l}\text { Assessment } \\
\text { of geological } \\
\text { environment } \\
\text { safety and } \\
\text { bearing } \\
\text { capacity } \\
\text { of Ankang } \\
\text { region }\end{array}$} & \multirow{2}{*}{ Structural stability } & \multirow{2}{*}{\multicolumn{2}{|c|}{$\frac{\text { Fracture activity }}{\text { Peak acceleration of ground motion }}$}} \\
\hline & & & \\
\hline & \multirow{5}{*}{ The degree of vulnerability } & \multirow{5}{*}{$\begin{array}{c}\text { The degree } \\
\text { of } \\
\text { vulnerability } \\
\text { to } \\
\text { geological } \\
\text { disasters }\end{array}$} & Landscape \\
\hline & & & Rock-soil body \\
\hline & & & Slope \\
\hline & & & Structure \\
\hline & & & Annual rainfall \\
\hline
\end{tabular}




\begin{tabular}{|c|c|c|}
\hline & & Human engineering activities \\
\hline \multirow{2}{*}{ Water and soil environment } & \multicolumn{2}{|r|}{ Groundwater quality（diving） } \\
\hline & \multicolumn{2}{|r|}{ Soil erosion intensity } \\
\hline \multirow{5}{*}{ Shallow geothermal } & \multirow{5}{*}{$\begin{array}{l}\text { Shallow } \\
\text { geothermal } \\
\text { suitability }\end{array}$} & Formation lithology \\
\hline & & Aquifer thickness \\
\hline & & Groundwater runoff velocity \\
\hline & & Comprehensive heat transfer coefficient \\
\hline & & Specific heat capacity \\
\hline Geological relics & & Heritage type zoning \\
\hline
\end{tabular}

\subsection{Index weight}

The evaluation index value is the measure of the whole system attribute characteristic, and the weight is the measure of the index. According to the subjective needs of the assessment of geological environment capacity and the advantages and disadvantages of the comprehensive weight calculation method, AHP in the subjective weight determination method is used to calculate the weight. Analytic hierarchy process ${ }^{[10]}$ is currently widely used to determine weight, which has certain advantages in analyzing complex decision-making problems with multiple objectives and criteria. Its main feature is the combination of qualitative and quantitative analysis, which expresses people's subjective judgment in quantitative form and deals with it scientifically.

According to the evaluation index, the importance of geological environment capacity in Ankang region was evaluated in pairs, and the importance of the index factors was determined, that is, the importance of evaluation index to geological environment carrying capacity. The scale of $1 \sim 9$ is used to indicate that the index has the least impact on the geological environment capacity, and 9 indicates the maximum. By means of expert rating, a number of 10 domestic experts (including engineering geology, hydrogeology, environmental geology, resources, geological disasters, etc.) were used to score the importance of the indicators respectively. The importance score of each index is obtained through statistical analysis. Then, by comparing the two indicators, the binary judgment matrix of the evaluation indicators is obtained.

Consistency test is required for the evaluation matrix, and the $C_{R}$ value is 0.087 , meeting the requirements of consistency test. According to the judgment matrix, the eigenvectors and eigenroots of the evaluation matrix are solved by MATLAB, and the weights of each index are finally determined, as shown in table 2 .

Table 2 weight of indicators

\begin{tabular}{|c|c|}
\hline Indicators & weight \\
\hline Active faults & 0.2486 \\
\hline Dynamic peak acceleration & 0.1102 \\
\hline
\end{tabular}

\begin{tabular}{|c|c|}
\hline The degree of vulnerability & 0.3815 \\
\hline Groundwater quality & 0.1346 \\
\hline Shallow geothermal & 0.0521 \\
\hline Soil erosion intensity & 0.0477 \\
\hline Geologic relic type & 0.0252 \\
\hline
\end{tabular}

It can be seen from the weight of evaluation indicators in table 2 that the degree of vulnerability to geological disasters and active faults are the leading factors affecting the geological environment capacity in Ankang region. Secondly, the dynamic peak acceleration and groundwater resources were obtained. Other indicators have less influence.

\section{Assessment of geological environment capacity of Ankang region}

\subsection{Evaluation unit division}

Due to the complexity and difference of geological environment factors of ankang in different regions, it is necessary to divide the whole target area into several evaluation units in order to carry out comprehensive evaluation of geological environment accurately and scientifically. At the same time, the geological environmental assessment is ultimately to further develop reasonable planning and use, and the division of the evaluation unit is good for the structure of the units at various levels.

The division of evaluation unit is usually based on the difference between geological and environmental conditions and the principle of "region similar, regional difference". Currently, there are three types of evaluation units that are used in geological and environmental evaluation: the rule unit, the irregular unit, and the synthesis. In the related evaluation work, it is a common way to divide administrative regions into districts. The advantage of this method is that the collection and statistics of data are relatively easy and administrative management is convenient. 
Taking into account the above considerations and the working accuracy of the single index layer, this evaluation is based on the spatial analysis function of MapGis. The current situation of geological environment in Ankang is evaluated by means of grid division of evaluation area, and the fracturing specification is determined to be $0.5 \mathrm{~km}$ $* 0.5 \mathrm{~km}$, and a total of 8770 reference units are divided (see figure 1).

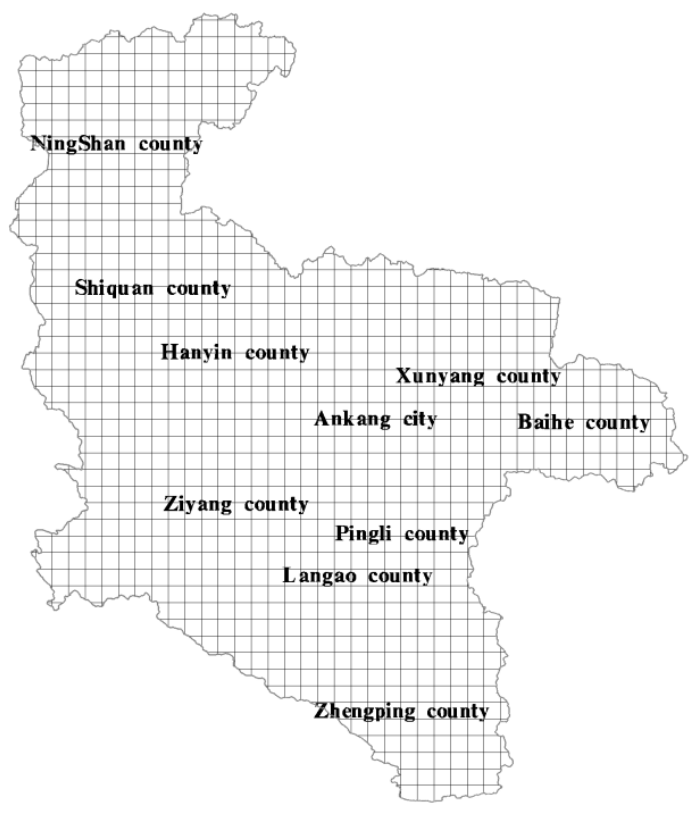

Figure 1 Dissecting the Grid of GECC Evaluation Unit in Ankang Region

\subsection{Evaluation result partitioning}

Based on the grid division method and the spatial analysis function of MapGIS, the superposition analysis of each index layer in Ankang region is carried out. Each section unit automatically acquies quantized values of each factor to form a GIS grid layer of individual indicator factors. Based on the calculation value of cell, the weighted comprehensive evaluation model of each grid is calculated, and the geological environment capacity of Ankang region is evaluated.

According to the analysis and calculation results of grid layer, the comprehensive coefficient range of capacity of the unit is $0 \sim 3.20$, and the score value indicates the suitability level of geological environment. The higher the value is, the lower the suitability is, and the worse the capacity level of geological environment is. A cell whose comprehensive evaluation value is zero represents the distribution area of strong restrictive factors (geological relic protection). Based on the corresponding relationship between the distribution characteristics of the assessment results of suitability and the individual indicators, the natural breakpoint method ${ }^{[11]}$ was adopted to divide the assessment results from the perspective of geological environment capacity. It is divided into: geological environment protection and development zone $(E<2.1)$, geological environment restoration zone $(2.1 \leq \mathrm{E}<2.6)$, and geological environment maintenance zone $(\mathrm{E}>2.6)$. Finally, the line parameters were set and the graphic elements were noted. After manual deletion and combination, the GECC evaluation zoning map of Ankang region was obtained (see figure 2).

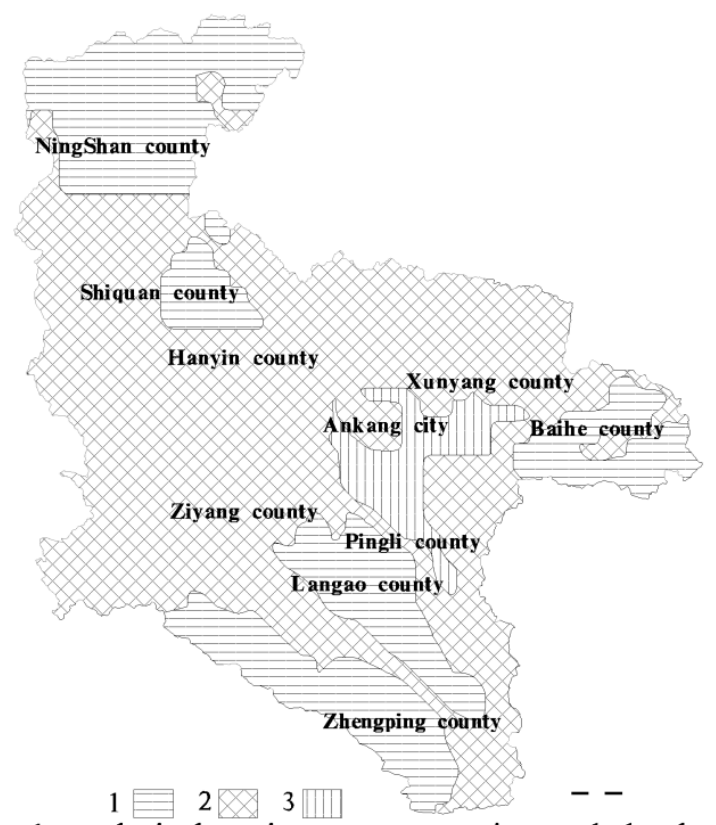

1. geological environment protection and development

2. geological environment restoration zone

3. geological environment maintenance zone

Fig. 2. Geological Environmental Capacity Partition map of Ankang Region

Geological environment protection and development zone $(\mathrm{E}<2.6)$ distributed in lutou mountain - trestle mountain, Erjiaping - Erlang ping - hongjiaping, Shuanglong bridge - niutoudian area, and Yuhuangmiao and yaoping street around baihe county, and about 2636.6 $\mathrm{km}^{2}$ of looping street. The geological disasters in this region are not easy to occur, or are relatively low and easy to occur locally. The structure is stable, and the level of safety and capacity is high. The geological conditions in the area are better, the vegetation coverage is higher,and the water is richer and better, and it is also a suitable area to develop the shallow geothermal energy. In addition, the consideration of the limiting factors in the general evaluation model, it also includes all the various geological relics and protected areas of the province, which is the area of zero.

The geological environment restoration area $(2.1 \leq \mathrm{E}<2.6)$ is mainly distributed in most areas of Ankang with an area of about $5382.4 \mathrm{~km}^{2}$. Due to the influence of geological conditions in southern shaanxi, the geological disasters in this area are easy to occur or high to occur. In addition to being affected by regional geological and geomorphological conditions, mining, housing construction, transportation facilities construction and other activities have resulted in serious geological disasters and soil erosion, resulting in poor geological environment security and bearing capacity of the region. Development and construction activities need to further deal with geological calamity, irrational development and construction activities can induce secondary geological disasters and other geological environment problems. 
The geological environment maintenance $(\mathrm{E} \geq 2.6)$ area is about $413.1 \mathrm{~km}^{2}$. The main distribution is in the Ningshan county along the main road, and it's consistent with the movement. This area is a high occurrence area of landslide and slippery flow. Due to the geological landform and slope excavation and other factors, the landslide flow is high and easy to occur. Large-scale mining of large quantities of mines and coal has resulted in collapse of the ground surface and erosion problems.

\section{Conclusions and Suggestions}

(1) By analyzing the theories and methods of geological environment capacity, we have quantified the strong limiting factors, improved the synthetic evaluation models, and gave a quantitative evaluation model of the geological environment, and the assessment of the geological conditions of the area, and the results of the evaluation to provide a reference and basis for future planning and construction. The geological environment capacity of the area is evaluated, and the evaluation results provide reference and basis for its future planning and construction.

(2) Combined with the process of constructing index system of the geological environment evaluation, 16 specific indicators were selected from three aspects of hydrogeological environment, engineering geological environment and environmental geological problems based on the geological environment ontology attribute and considering the spatial conditions, resource conditions, restriction conditions and advantage conditions of the geological environment, and the GECC evaluation index system in Ankang region was established. The idea of constructing this evaluation index system can be used as a reference for the construction of GECC evaluation index system in other regions.

(3) The geological environment capacity evaluation model constructed in this paper is also applicable to GECC evaluation in other areas. But in the quantitative grade of the index, because there is no best way to do it, it's more arbitrary, it's still a matter of future research.

\section{References}

1. Liuyang Wang.Research on safety comprehensive evaluation index system of geological environment -Based on the comprehensive evaluation of geological environment safety in Dazhou as an example," Chengdu Univerisity of Technology (CDUT),2013.

2. Dang Lijuan, Xuyong."Review of research progress in carrying capacity of water resources," Research of Soil and Water Conservation .vol.22, no.3, pp.341-348, 2015.

3. MA Chuan-ming, MA Yi-hui." Tentative Investigation of Bearing Capacity of Geological Environment for Sustainable Development," Environmental Science and Technology. vol.30, no.8, pp.64-65, 2007.
4. Yu Zhishan, Ma Chua-ming, Ning Libo." Study on the bearing gapacity of geologic of geologic environment for sustainable development." Gansu Geology, . no.2, pp.81-84, 2008.

5. Xia yucheng."Bearing capacity of geological environment in coal-mining area and its assessment . "Coal Geology \&Exploration. vol.31, no.1, pp.5-8, 2003.

6. Wei Zixin,Zhou Aiguo,Wang Hanmei." Study on Evaluation of Geological Environmental capacity." Shanghai Geological. no.1, pp.40-41, 2009.

7. Zhang Maoxing, Wang Rao." Research on the evaluation of the carrying capacity of geological environment based on its risk level." Geological Bulletin of China. vol.37, no.2,

pp.467-475, 2018.

8. Chen Shu. Research on safety comprehensive evaluation index system of geological environment - Based on the comprehensive evaluation of geological environment safety in Dazhou as an example. Chengdu University of Technology,2016.

9. Xia Jisheng,Kuai Linie,Liu Benyu,et al.Study on urban geoenvironment load capacity for Kunming's development based on GIS [J].Earth and Environment, vol.36, no.2, pp.148-154, 2008.

10. Yang Le, Peng Haiyou, Zhou Molin. Assessment of Geological Environment Carrying Capacity of Fengjie County Based on AHP. Journal of Chongqing Jiaotong University(Natural Science). vol.33, no.2, pp.95-99, 2014.

11. Wang Kuifeng, Han Xiangyin, Zhang Taiping. "The construction and application of the index system of geo-environmental carrying capacity in Shandong peninsula." Environmental Pollution \& Control. vol.35, no.9, pp.29-34, 2015. 